We accept that the ex-offender should forfeit certain rights but why should this apply to ex-patients? Legal restrictions on current patients are kept to a minimum (the Mental Health Act, the law on epilepsy and driving) and there would have to be sound reasons for introducing new restrictions on ex-patients.

Most questions about the functioning of juries remain matters of speculation rather than empirical enquiry. There is some research by social psychologists in the USA, looking at "experimental" juries and the way in which they make up their minds but there is no similar research on actual juries. Research in the area is not encouraged, perhaps to preserve the mystique of "twelve good (wo)men and true". In fact, it would be illegal to do such research as it is a contempt of court to ask a juror about events in the juryroom, even when the trial is over. In the absence of information to the contrary, there is no reason to assume that the ex-psychiatric patient cannot participate fully in this mysterious process.

\title{
Psychiatry and the media
}

\section{Are psychiatrists too "heartless"?}

\section{'Affairs of the Heart'*}

\author{
RaJendRa D. Persaud, Honorary Senior Registrar, Bethlem Royal and Maudsley \\ Hospitals; Research Worker, Institute of Psychiatry and Institute of Neurology
}

'The Heart has Reasons', scheduled for broadcast on 21 February, is the film which launches a major new Channel 4 series of films called 'Affairs of the Heart'. The series purports to be a broad view of how the health of the heart is "... central to our whole well-being, both spiritually as well as physically...".

However, central to the well-being of the jaded hacks present at the preview was the plentiful supply of alcohol and clotted cream scones - surely a bizarre choice of refreshment for a series which later goes on to include 'Mysteries of a Broken Heart' (28 February), which investigates the causes of heart disease; 'Scotland the Grave' ( 7 March), which asks why Scotland has the highest level of fatal coronary heart disease in the world; 'Counter Attack' (14 March), which looks at resuscitation training currently available in metropolitan centres; 'It Won't Happen to Me' (21 March), which examines the life-style changes necessary to prevent heart problems; and finally, 'After the Attack' (28 March), which focuses on radical ideas regarding long-term therapy for heart patients, and in particular the work of Dr Peter Dixon at the Charing Cross Hospital.

Originally this first film, 'The Heart has Reasons', was to be broadcast on Valentine's Day, 14 February, but got re-scheduled to a week later. The film's central theme was "... making a connection between the heart of Valentine's day and the arts, to * Report on preview showing of first film in Channel 4's new series 'Affairs of the Heart', 7 February 1991. the physiological heart". One of the important scenes was an open heart operation set to music; this was meant to symbolise a juxtaposition of the two central themes of the film. However the producer, Mark Kidel, admitted sheepishly after the showing that the music had not been played during the operation itself, as strongly suggested by the film, but was dubbed in afterwards.

The psychologist James Hillman popped up again (see Freud Museum conference briefing, Psychiatric Bulletin, February 1991, 15, 102), only this time he provided a commentary to the effect that there were aspects of the heart which modern medicine could not comprehend, which included conclusions such as it is only since the heart began to be viewed as merely a muscular pump that heart disease has increased. Perhaps there are aspects of James Hillman which modern medicine does not comprehend.

I asked the producer, Mark Kidel, why he had neglected to include in the film any experts who had done serious work on the link between emotional states and physical conditions. He replied that science was all "speculation and ideology" anyway, and that since one of the psychotherapists in the programme had trained in Switzerland, he must have a medical degree. Kidel maintained that doctors, and perhaps particularly psychiatrists, ignored the 'heart' too much in their dealings with patients.

Well, perhaps psychiatrists are too 'heartless', but is that worse than being too brainless? 